Est Ag 47 (2012) 373-389

\title{
Hacia el tratado moderno de Iglesia y la Escuela de Salamanca
}

\author{
IGNACIO JERICó BERMEJO*
}

RESUMEN Fue probablemente en el curso 1555-56 cuando Pedro de Sotomayor ( $\uparrow 1564)$ comentó la $I^{\mathrm{a}}, \mathrm{I}^{\mathrm{a}} \mathrm{e}, \mathrm{q} .1^{\mathrm{a}}$, art. 10 , de la Suma de sto. Tomás, dando a sus alumnos un verdadero tratado de teología de la Iglesia o Eclesiología. Aquí presentamos también la exposición que hicieron otros profesores de la Universidad de Salamanca como Juan de la Peña y Mancio del Corpus Christi.

PALABRAS CLAVE: Eclesiología, Escuela de Salamanca, Juan de la Peña, Mancio.

KEY WORDS: Church's Theology, University of Salamanca, Juan de la Peña, Mancio.

ABSTRACT: It was probable during de scholar year 1555-56 when Pedro de Sotomayor $(\uparrow 1564)$ has presented the commentary to $\mathrm{II}^{\mathrm{a}}, \mathrm{II}^{\mathrm{a}} \mathrm{e}, \mathrm{q} .1^{\mathrm{a}}$, art.10, of the Summa of Saint Thomas, giving his students an exposition of the theology or the Church or Ecclesiology. Here, whe present the exposición made by others professors of the University of Salamanca as Juan de la Peña or Mancio del Corpus Christi.

Fue con toda probabilidad en el curso de 1555-15561 cuando el entonces catedrático de Vísperas de la Universidad de Salamanca, Pedro de Sotomayor (†1564), expuso su comentario al artículo décimo de la cues-

* Doctor en Teología, especialista en la problemática teológica del s. XVI.

1 Sobre la fecha en que expuso Pedro de Sotomayor el comienzo de la Secunda Secundae, cf. JERICo BERMEJo, I., Doctrina fidei catholica. El artículo de fesegún D. Chaves, $D$. de Cuevas y P. de Sotomayor: Scriptorium Victoriense 31 (1984): 248. 
tión primera de la Secunda Secundae (cf. Sevilla. Biblioteca de la Universidad, ms. 333-53) proporcionando de esta forma a sus alumnos una exposición sobre la teología de la Iglesia. Aquí va a hablarse ahora de las explicaciones salmantinas dadas por dos salmantinos del siglo XVI que, como Sotomayor, realizaron asimismo su personal exposición sobre la realidad de la Iglesia: Juan de la Peña y Mancio de Corpore Christi.

\section{Introducción general y texto de Juan de la Peña (1559)}

\section{INTRODUCCIÓN GENERAL}

Al comentar el artículo décimo de la cuestión primera de la Secunda Secundae procede Peña al igual que lo hiciera Sotomayor desarrollando la línea ya marcada por Bartolomé Carranza en San Gregorio de Valladolid en el curso de 1540-1541. En este colegio habían perfeccionado sus conocimientos de teología el uno y el otro. Extraño es de todas formas que, como se dirá a continuación, fuera precisamente Mancio de Corpore Christi, no formado en San Gregorio, quien siguiera la misma línea, en su comentario al artículo décimo de la cuestión primera de la Secunda Secundae, de lo expuesto por Juan de la Peña en Salamanca durante el curso de 1559-1560.

\section{Autores}

Nació Juan de la Peña ${ }^{2}$ en Valdearenas (Guadalajara) en 1513 y, tras haber permanecido cinco años como benedictino en Toledo, donde recibió por cierto la formación teológica, solicitó en 1540 hacerse dominico, siendo admitido en el convento de San Pedro Mártir. Sus superiores dominicos lo enviaron a perfeccionar los estudios a Valladolid, al colegio dominicano de San Gregorio. Allí tuvo como maestros a Bertolomé Carranza y a Melchor Cano. Terminados estos sus cursos, empieza a actuar de profesor en el mismo colegio de Valladolid. Al principio de 1559, tal como se mostrará a continuación, comienza a exponer la cuestión primera de la Secunda

2 Biografía. Cf. Jericó Bermejo, I., La Escuela de Salamanca del siglo XVI. Una pequeña introducción. (Madrid 2005) 206-207; Sobre los comentarios salmantinos la Secunda Secundae. Profesores y obras: Verdad y Vida 44 (2006) 126. Tanto en uno como el otro escrito se ha colado una errata, la que dice que Peña explicó desde 1551 hasta 1559 en San Esteban. Se quería haber dicho ahí en San Gregorio. No expuso él entonces sus lecciones en Salamanca, sino en Valladolid. 
Secundae. Pero, ¿no expuso este profesor esta materia en esa fecha en la Universidad de Salamanca desde la cátedra de Prima a finales de octubre del curso de 1559-1560?

El catedrático de Prima de la Universidad de Salamanca era en 1559 Domingo de Soto; pero las clases corrían a cargo de un sustituto ya que él se había jubilado. En este caso era el sustituto Ambrosio de Salazar. A partir del curso de 1559-1560 tocaba exponer en esta cátedra de Salamanca, propiedad de Soto, las primeras cuestiones de la Secunda Secundae. En esta universidad solía comenzar el curso en octubre, en la fiesta de San Lucas, y es un hecho que quien comenzó este curso a exponer no fue Salazar, sino el Maestro Vicente, el cual sólo explicó la materia de los ocho primeros folios del manuscrito T 19 existente en la Biblioteca General de la Universidad de Coimbra (Portugal). Lo hizo debido a que había fallecido Ambrosio de Salazar y se estaba todavía a la espera de que se nombrara al nuevo sustituto. Fue precisamente Juan de la Peña ${ }^{3}$ el nombrado. Y comenzó éste su explicación por el inicio mismo de la cuestión primera, artículo primero de la Secunda Secundae, por estimar al parecer que era pocas las lecciones hasta entonces explicadas y que era conveniente comenzar desde el principio.

Muere un año después el catedrático de Prima, Domingo de Soto (1560). Pedro de Sotomayor, catedrático de Vísperas, oposita entonces a la cátedra vacante y la obtiene. En consecuencia queda vacante la de Vísperas. La obtiene por oposición Juan de la Peña el 24 de enero de 1561. Fue entonces cuando su Orden concedió a éste el título de maestro. Murió Peña en Salamanca el 28 de enero de 1564. A la oposición por la vacante de su cátedra de Vísperas se presentaron el dominico Juan Gallo y el agustino Juan de Guevara, siendo éste quien la obtuvo al fin. Y es en el mismo año de 1564 cuando muere el catedrático de Prima, Pedro de Sotomayor. Se espera que se presente a la oposición Juan de Guevara, catedrático de Vísperas; pero renuncia él a ello. Los dominicos habían llamado opositar a Mancio de Corpore Christi, que es desde 1548 el catedrático de la cátedra mayor de Santo Tomás en la Universidad de Alcalá. Al no opositar nadie más a la cátedra, quedó proclamado Mancio como el catedrático.

3 "En 1559 muere Ambrosio de Salazar [...]. Sus superiores le envían [a Juan de la Peña] a Salamanca a cubrir este puesto [...]. Pero para ello tuvo que acelerar su graduación en teología. Primero obtiene el título de bachiller en teología por la Universidad de Valladolid (9 de octubre de 1559), accediendo así a la sustitución de Soto en la cátedra de Prima de Salamanca, de la que tomó posesión e inició las clases el miso mes de octubre de 1559. Este curso 59-60 explicó la Secunda Secundae de la Suma". BELDA PLANS, J., La Escuela de Salamanca. (Madrid 2000) 763. 
Mancio de Corpore Christi ${ }^{4}$ había nacido en Becerril de Campos (Palencia) alrededor del año 1500. Profesó como dominico en el Convento de San Esteban (1524). Estudio la teología en Salamanca. Tuvo como maestros a Vitoria y a Soto. Marchó a Sevilla con la intención de partir como misionero a América (1530). Desiste al fin en su intención y permanece en Sevilla al ser admitido como colegial becado en el colegio de Santo Tomás. A él se le llama desde Salamanca en 1535 y se le envía a París. Es en 1546 cuando obtiene los grados de bachiller y de maestro en teología en Sigüenza. Al marchar en 1546 Melchor Cano a Salamanca para ocupar la cátedra de Prima por la muerte de Francisco de Vitoria, fue Mancio quien se ocupó de las lecciones de la cátedra mayor de Santo Tomás en la Universidad de Alcalá.

Al haber renunciado Domingo de Soto, concretamente en 1548, a su cátedra de Vísperas de la Universidad de Salamanca, fue Mancio quien había opositado a ella; pero la victoria cayó en la persona de Juan Gil de Nava, el cual se había ocupado precisamente de sustituir en las lecciones de Prima a Francisco de Vitoria antes de morir éste (1546). Así las cosas, Mancio regresa a Alcalá en 1548 al haber obtenido la cátedra mayor de Santo Tomás, la que dejara dos años atrás Melchor Cano. En ella permanecerá hasta 1564. Ante la muerte del profesor de Prima de la Universidad de Salamanca, Pedro de Sotomayor, se presenta Mancio a la oposición y la obtiene el 22 de noviembre de 1564. Comienza su exposición como catedrático el 23 de noviembre. Tal era la lección 25 del curso de 1564-1565. Comenzó entonces a explicar este catedrático por el inicio mismo del artículo décimo de la cuestión primera de la Secunda Secundae 5. ¿Quién explicó entonces aquel curso los nueve artículos anteriores? Según el ms. 5 de Palencia (Biblioteca del Cabildo de la Catedral) hubo alguien que expuso, no Sotomayor, las tres lecciones primeras del curso de 1564-1565 (fol. 2-8). Será a partir de la lección cuarta cuando explica las lecciones Cristóbal Vela 6 . Éste expuso 24 lecciones y llega hasta el artículo noveno?

4 Biografía. Cf. JeRICó Bermejo, I., La Escuela de Salamanca del siglo XVI. Una pequeña introducción. (Madrid 2005) 211, nota 518.

5 "25. Hinc incepit legere Manzio in cathedra primae horae, anno 1564, die vero 23 novembris. Et accepit possessionem cathedrae die 22 eiusdem mensis". Palencia. Biblioteca del Cabildo Catedralicio, $m s .5$, fol. 46v.

6 "Lectio 4. Hinc legit don Cristobl Vela propter mortem fr. Mag. Petri de Sotomayor, qui obiit in die sabbati in initio undecim virginum, quae fuit dies 21 octobris 1584)". Palencia. Biblioteca del Cabildo de la catedral., fol. 8r.

7 Cf. Jericó Bermejo, La fe por el tiempo. El artículo de fe según C. Vela (1564): Burgense 34 (1993) 541-549. 
Existen tres manuscritos de Peña sobre el inicio de la Secunda Secundae: el 333-53 de Sevilla (Biblioteca de la Universidad), el T 19 (1852) de Coimbra (Biblioteca General de la Universidad) y el Ott. lat. $1046 \mathrm{de}$ Roma (Biblioteca Apostólica Vaticana) ${ }^{8}$. Aquí se ha elegido para dar a conocer su exposición sobre la Iglesia el 333-53 de Sevilla. Sorprende a este respecto que haya habido quienes, al parecer, hubieran señalado que este manuscrito viene a ser resultado de lo explicado efectivamente por Peña en el curso de 1559-1560 desde Salamanca. ¿Cómo es que no se ha advertido que esto no puede ser, ya que los manuscritos de este curso académico son los otros dos, los cuales coinciden perfectamente entre sí salvo algún detalle que se debe a que fueron tomados de la misma lectura oral por dos oyentes diferentes? Pero se debe decir que el 333-53 es precisamente el que expuso Peña con el título obtenido de presentado ${ }^{9}$ en el inicio ciertamente del año 1559. ¿Dónde expuso esto el presentado? Hay que pensar, salvo prueba concreta al respecto, que impartiera las lecciones desde Valladolid, San Gregorio concretamente. De hecho, se dejó escrito hace años: "En 1559 muere Ambrosio de Salazar [...]. Este hecho precipita los acontecimientos. Sus superiores lo [a Juan de la Peña] envían a Salamanca a cubrir ese puesto [de explicar en la cátedra de Prima como sustituto], librándole al mismo tiempo de las presiones de la Inquisición en Valladolid. Pero para ello tuvo que acelerar su graduación en teología"10.

Suele ser mi costumbre, lo reconozco, publicar los manuscritos tanto en la lengua original latina como en su traducción al español. Si sólo puedo hacerlo en una lengua, prefiero realizar la exposición del texto en latín. Tal es el caso presente. ¿No debía entonces haber ofrecido más bien aquí el texto al menos del Ott. lat. 1046, ya que el de T 19 de Coimbra se encuentra publicado con la correspondiente traducción al español? ${ }^{11}$ Entiendo a este respecto que no hay necesidad de ello por ser textos iguales, como ya se ha dicho, el de Coimbra y el de Roma. Me permito señalar ahora pese a todo que es de interés el precisar cómo se han venido conociendo en el

8 Sobre la descripción de estos tres manuscritos, cf. JERICó BERMEJO, I., Sobre los comentarios salmantinos la Secunda Secundae. Profesores y obras: Verdad y Vida 44 (2006) 149-150.

9 "Aplícase [presentado] en algunas órdenes religiosas al teólogo que ha seguido su carrera y, acabadas sus lecturas, está esperando el grado de maestro". REAL ACADEMIA ESPAÑola, Presentado. Diccionario de la lengua española. Tomo II. (Madrid 11992 20) $1661 \mathrm{a}$.

10 BELDA PLANS, J., La Escuela de Salamanca. (Madrid 2000) 763.

11 Cf. PEÑA, J. De LA, Elesiología. Réplica a la Iglesia de Lutero. Salamanca 1987. 
tiempo estos tres manuscritos de Peña ${ }^{12}$. Asimismo digo decir yo que, pese de hallarse ya publicado en lengua original y en la correspondiente traducción española el artículo décimo de la cuestión primera de la Secunda Secundae ${ }^{13}$ del ms. 5 de Palencia que corresponde a Mancio ${ }^{14}$, me he permitido añadir un texto que llamo añadido y que versa concretamente sobre la autoridad del Sumo Pontífice. Y añado además que lo hago por razones de teología.

Si me permito presentar en este caso mi propia transcripción del texto latino, se debe a que me gusta dar al lector lo que está en el texto mismo, así como quiero en todo momento facilitar la lectura. Lo transcrito y publicado por mí es lo que no se debería hallar también en los manuscritos de Peña de 1559-1560. Ahora bien, da la casualidad de que el manuscrito de Mancio dice cosas propias además allí. Ya las hice notar yo en $1983^{15}$. Y lo que aquí se transcribe y publica de este catedrático de Prima es parte de lo propio que hay allí suyo de lo ya explicado por Juan de la Peña en Salamanca.

\section{Los manuscritos}

R. Hernández Martín publicó en 1987 la explicación de Peña al artículo décimo de la cuestión primera de la Secunda Secundae según el ms. T 19 de la Biblioteca de la Universidad de Coimbra. Manifestó al hacerlo que hay doctrina de Peña sobre el artículo décimo en tres comentarios más: ms. 333-53-1 de Sevilla, Ott. lat. 1046 de Roma y Vat. lat. 6993 también de Roma16. También anotó él de este último inmediatamente que "aparece entre los MSS [manuscritos] del canonista Francisco de Peña, copiado por éste probablemente del Ottob. lat. 1046, aunque permitiéndose bastantes variantes materiales en su redacción". Admitido esto, ha de establecerse entonces que son tres los manuscritos de Peña sobre el artículo décimo al depender lo escrito en el Vat. lat. 6993 de lo que se reproduce en el Ott. lat 1046.

12 Cf. Jericó Bermejo, I., Fides Ecclesiae tradita. El artículo de fe según J. De la Peña, M. De Corpore Christi y B. de Medina.: Scriptorium Vicotriense 33 (1986) 228.

13 Cf. Sarmiento, A., La Eclesiología de Mancio. II. Pamplona 15876.

14 Sobre la descripción del ms. 5 de Palencia, cf. JeRICó BERMEJO, I., Sobre los comentarios salmantinos la Secunda Secundae. Profesores y obras: Verdad y Vida 44 (2006)150-151.

15 Cf. Jericó Bermejo, I., Fides Ecclesiae tradita. El artículo de fe según J. De la Peña, M. De Corpore Christi y B. de Medina.: Scriptorium Victoriense 33 (1986) 130-131.

${ }^{16}$ Este manuscrito no se tiene en cuenta en este trabajo.. 
Por supuesto, estos tres manuscritos [ya no atiende ak expresarse así al Vat. lat 6993] surgen de Peña. De todas formas, conviene aclarar si vienen también de la misma explicación del profesor. No se plantea R. Hernández Martín esta cuestión; pero parece que, de alguna manera, no le ha pasado desapercibida. Hay por cierto existen entre los tres códices muchas variantes y, si vienen los tres de la misma explicación, ¿cómo es que difieren tanto? Dice entonces éste: "El manuscrito de Coimbra es de corte académico, que sigue de inmediato las lecciones del maestro, tal como saldrían de sus labios en las aulas; es para nosotros por eso el de más valor. El texto del Ottob. lat. es algo más reducido suprimiendo algunas citas y párrafos; pero sigue el mismo orden, y parece tener de cerca las lecciones de clase. Más cuidado y sintético es el de la Universidad de Sevilla; es una reelaboración contemporánea que se permite un cambio notable del texto como también del orden de los puntos dentro de la misma cuestión. [...] Nosotros reproduciremos el manuscrito de Coimbra, pero teniendo siempre delante los otros, para actuar con mayor seguridad en los casos de duda".

Estos tres códices con la explicación de Peña sobre el artículo décimo, precioso ciertamente, sobre la autoridad de la Iglesia, dan lugar por cierto a muchos interrogantes y los mismos deben ser contestados desde la mayor objetividad posible. Al parecer, desconocía R Hernández Martín ciertas aportaciones al respecto publicadas en 1986; es decir, un año antes de que se editara lo que él subtitula Réplica a la Iglesia de Lutero. Conviene lanzar la vista atrás ahora. Sobre el T 19 de Coimbra llamaba la atención en 1935 V. Beltrán de Heredia. Aunque el nombre de Peña no aparece al principio del códice, no dudó este sabio investigador en atribuirlo a Juan de la Peña. Fue en 1953 cuando L. Pereña daba a conocer como de Peña también el manuscrito Ott. lat. 1046 existente en la Biblioteca Vaticana. El códice portugués y el ms. 333-53 de Sevilla eran conocidos por C. Pozo ciertamente en 1959; pero este autor nada dijo entonces del de Roma. Seguramente, lo desconocía. Así las cosas, se plantea en este momento la pregunta fundamental respecto a estos tres códices de Peña: el de Sevilla, el de Coimbra y el de Roma.

El T 19 y el Ott. lat. 1046 contienen ciertamente la misma explicación; pero, ¿contiene también la misma explicación el ms. 333-53 de Sevilla? La respuesta ha de ser aquí negativa. Es [la de éste] una explicación diversa

17 Todo cuanto precede en este apartado titulado los manuscritos ha sido publicado por mí. Aquí no se reproducen las notas. Cf. JERICó BERMEJO, I., La Escuela de Salamanca del siglo XVI. Una pequeña introducción. (Madrid 2005) 207-211. 
ciertamente de la recogida por los manuscritos de Roma y de Coimbra. El folio 1r del manuscrito sevillano dice: "Comienzan los comentarios a la Secunda Secundae de Santo Tomás por el reverendo fray Juan de la Peña, presentado, comenzados sobre el inicio del año 1559". Este manuscrito de Sevilla lleva la explicación seguida hasta el artículo segundo de la cuestión veintidós de la Secunda Secundae (fol. 250r). Peña se encontraba ciertamente como profesor al inicio de 1559 en San Gregorio de Valladolid. Es verdad que, ese mismo año y ante la muerte de Ambrosio de Salazar, tuvo que marchar [Peña] a Salamanca para ocuparse de la sustitución de la cátedra Prima, trabajo que inició el 30 de octubre de 1559.

En la cátedra de Prima de Salamanca habría comenzado aquel curso de 1559-1560 Ambrosio de Salazar como sustituto de Soto la explicación del artículo primero de la cuestión primera de la Secunda Secundae. El curso se iniciaba en Salamanca el 19 de octubre; pero Ambrosio de Salazar muere el 10 de septiembre de 1559. Como Peña no llegó a su cátedra hasta el 30 de octubre, ¿quién explicó entonces la Secunda Secundae hasta que él llegara? ¿Continuó Peña una vez en posesión de la cátedra lo explicado por el sustituto accidental o lo volvió a repetir? Ciertamente, fue ese sustituto accidental el Maestro Vicente y fue él quien empezó la explicación de la Secunda Secundae. Se halla recogida la misma en los siete primeros folios de Ott. lat. 1046. Al llegar Peña, prefirió comenzar lectura desde el principio, de la Secunda Secundae por supuesto.

Ciertamente, explicó Peña en esta prestigiosa cátedra salmantina en los últimos meses de 1559 la cuestión primera de la Secunda Secundae. El resultado de esto es que explicó esta cuestión primera en dos ocasiones aquel año de 1559. Lo hizo primeramente en los primeros días del año, muy probablemente en Valladolid. Así lo marca el inicio del códice de Sevilla. Y lo hizo en segundo lugar en Salamanca desde la cátedra de Prima en los primeros días del curso de 1559-1560. ¿Confirman esto quizás los manuscritos de Coimbra y de Roma? El folio 64r del manuscrito $\mathrm{T} 19 \mathrm{y}$ los folios 47r-47v del manuscrito Ott. lat. 1046 reconocen que el 15 de diciembre de 1559 iba Peña explicando en Salamanca por el artículo décimo de la cuestión primera de la Secunda Secundae.

Quien tiene en sus manos y lee ahora el artículo décimo de los tres manuscritos traza de inmediato una línea de separación neta entre ellos. A un lado colocará el mismo el ms. 333-53 de Sevilla y, al hacerlo, no le cabrá duda alguna de que ese manuscrito contiene ciertamente lo expuesto por Peña desde el principio de 1559 (fol. 1r). Al otro lado colocará el contenido de los otros dos códices: T 19 y. Ott. lat. 1046. Tal fue, por supuesto, la explicación impartida por Peña desde octubre de 1559 en Salamanca desde la 
cátedra de Prima. Por supuesto, los tres códices son de Peña; pero el de Sevilla contiene su lectura de Valladolid. Contienen en cambio los otros dos la lectura del curso empezado en Salamanca en octubre de 1559. Los tres son de 1559; pero no son los tres del mismo curso.

No hay entonces razón para tener que explicar ahora las diferencias del de Sevilla con los otros dos, diciendo que se trata de reelaboración alguna. Cuando los tres manuscritos acometen el mismo problema de quién es la verdadera Iglesia, dicen los tres que es la sometida al papa de Roma. Es a partir de ahí cuando aparecen además netamente las diferencias en los dos grupos. Mientras el ms. 333-56 de Sevilla dice que el Papa vive todavía y es Paulo IV, dicen en cambio el T 19 y el Ott. lat. 1046 que ya no vive el Papa y que la Iglesia se encuentra a 15 de diciembre de 1559 en estado de Sede Vacante. Todo es coherente. Paulo IV murió el 18 de agosto de 1559. Su sucesor: Pío IV, no fue elegido hasta el 25.12.155917.

Aquí se va a ofrecer a continuación la exposición que realizó Juan de la Peña sobre la Iglesia a principios de 1559 , probablemente en el colegio vallisoletano de Valladolid, la que aparece en el ms. 333-53 de la Biblioteca de la Universidad de Sevilla ${ }^{18}$.

\section{EL TEXTO DE PEÑA (1559)}

[fol. 38v] [...] Art. 10. Utrum ad summum pontificem pertineat symbolum ordinare. Conclusio est quod ad solam auctoritatem papae pertinet symbolum ordinare. Iste articulus habet dotrinam gravissimam et pro tempore maxime necessariam, quia tractat de auctoritate papae et concilii in ordine ad res fidei. [....]

[1.] [fol. 39r] [...] Pro intelligentia huius materiae oportet primo explicare quid sit eclesia. Hoc ergo nomen eclesia est graecum et significat evocatio sive convocatio sive contio evocata. Unde quia eclesia Christi congregatur in unam fidem. Fides vero est ex auditu et vocantur homines ad Christum per fidem et praedicationem evangelii, ut dicit Paulus, Auditus

18 Si se desean noticias con la descripción de los manuscritos sobre la Secunda Secundae de Juan de la Peña, y especialmente del ms. 333-53 de Sevilla, cf. Jericó Bermejo I., Sobre los comentarios salmantinos a la Secunda Secundae. Profesores y obras (siblo XVI): Verdad y Vida 54 (2006) 148-150. 
autem per verbum Christi. Idem. Ista congregatio sic convocata appellatur ecclesia.

$2 .^{\circ}$ notandum quod ecclesia cum sit nomen comune, appellatione non solum significat congregationem bonorum, sed etiam ${ }^{19}$ malorum iuxta illud, Odivi ecclesiam malignantium. At vero ecclesia catholica sive apostolica est quasi nomen singulare huius congregationis christianae. Aliquando vero quasi per anthonomasiam nomine ecclesiae absolute intelligimus ecclesiam catholicam, ut cum dicimus, Ego teneo quod tenet eclesia. Unde quando profertur nomen ecclesiae: Tamen si addatur aliquid quo determinetur hoc nomen ad congregationem malorum et infidelium, semper intelligimus ecclesiam catholicam, sicut nomine apostoli intelligimus Paulum, et nomine philosophi intelligimus Aristotelem.

3. ${ }^{\circ}$ notandum quod ista ecclesia catholica habet duas [fol. $\left.39 \mathrm{v}\right]$ partes, alteram iustorum, alteram vero peccatorum. Et ego credo quod hoc explicatur in symbolo cum dicimus, Credo unam sanctam eclesiam, hic explicatur tota congregatio ecclesiae, et bonorum et malorum. At vero cum sequitur, sanctorum communionem, credimus quod in ista ecclesia sunt tali aliqui sancti qui conmunicant sibi suas operas et satisfactiones. Aliqui vero dicunt quod illud sanctorum communionem solum ponitur apositive ad explicandum primam partem. Unde illud non restringitur ad bonos.

$\mathrm{Ab}$ ista congregatione separantur haeretici quia non sunt membra ecclesiae coniuncta, sed precisa eo quod tantum retinent characterem et praeciduntur quia non habent fidem qua deberent uniri corpori ecclesiae per fidem quidem informem aliquo modo, per formatam vero perfecte.

$\mathrm{Nec}$ tantum sequitur ex hoc quod haeretici non pertineant ad ecclesiam aliquo modo, quia alias sequeretur quod ecclesia non potest illos punire iure. Consequens est falsum. Patet quia ecclesia iustissime punit haereticos, tunc poenis spiritualibus excommunicando, tunc temporalibus, etiam occidendo si opus fuerit. Sequela vero patet, quia ut ait Paulus 1.ae ad Cor. 5., De his qui foris sunt nihil ad nos attinet vindicare. Non ergo heretici sunt omnino foris, quia aliquo modo pertineant ad ecclesiam. Alias non puniret illos sicut non punit infideles paganos. Pertinent ergo ad ecclesiam haeretici, non quod sint membra coniuncta, sed sicut membrum praecisum a corpore humano pertinet ad eundem hominem a quo precisus est. Si enim prescindatur una manus, illa manus presisa mea est et ad me expectat habere cum anima illius, et conteni ibi. Et si quis illam auferret, [fol. 39br] faceret mihi iniuriam. Haeretici ergo sunt praecisi ab ecclesia

19 Sigue palabra tachada: bonorum. 
tanquam membra. Ad illam ergo spectat habere animam illorum et punire et curare ut revivat si fieri potest.

Item excommunicati sunt membra coniuncta non solum per characterem, sed per fidem, quia sunt fideles. At vero dicuntur aliquo modo praecisi quia sunt privati communibus ecclesiae suffragiis et communicatione externa, et ideo caute loquendum est. Et certe sunt intelligendi doctores quando dicunt quod excommunicati sunt praecisi ab ecclesia.

Homines vero peccatores christiani baptizati sunt vera membra ecclesiae etsi non viva, unde sequitur quod ecclesia catholica, ut dicebamus, mixta est ex bonis et malis christianis baptizatis quo fit ut eclesia catholica est congregatio fidelium baptizatorum, qui scilicet sunt sub una fide et communicatione sacramentorum. Hoc dico quia chatecumeni antequam baptizentur etiamsi habeant veram fidem, non dicuntur partes et membra ecclesiae quia non sunt uniti et incorporati per baptismum et signati per charaterem. Unde quousque profiteatur fidem in baptismo, habent se sicut novitii religionum. Et sic si velint deserere fidem, non possunt compelli ad manendum, sicut neque novitii religionum. Ita illum non potest ecclesia excommunicare licet aliis viis, ut postea dicemus, posset punire.

[2.] Ex his omnibus colligimus definitionem ecclesiae. Eclesia catholica, id est universalis, est congregatio fidelium visibilis complectens simul bonos et malos.

Ista conclusio est contra aliquos haereticos qui dixerunt quod eclesia [fol. 39bv] est congregatio sanctorum et iustorum. Alii vero peius dixerunt quod ecclesia est congregatio praedestinatorum sive fidelium sive infidelium, et quod gratia quae unit membra ecclesiae est gratia praedestinationis. Isti errores fuerunt Wiclef et Ioannis Us, ut patet concilio constantiensi errore primo, errore 6. et 21. et sessione 8. Et recensentur errores Wiclef dicentis quod papa peccator non pertinet ad ecclesiam. Lutherani etiam tenent istos errores. Dicunt quod ecclesia est congregatio solum iustorum. Et illi magis consequenter loquuntur, quia isti credunt quod per solam fidem iustificatur homo. Unde apud 20 illos valet ista consequentia, Est fidelis, ergo iustus; est christianus per veram fidem Christi, ergo iustus. E converso, Non est iustus, ergo non est fidelis. Sed omnia ista sunt haeretici.

Et conclusio nostra est catholica et verissima. Et probatur ex evangelis. Primo Matth. 3., ubi Ioannes Baptista ${ }^{21}$ comparat ecclesiam areae. Dicit: Ventilabrum in manu sua est et permundabit aream suam. Dei ergo est ista

${ }^{20}$ Sigue palabra tachada.

21 Sigue palabra tachada: dicit. 
area. At vero area permixta est ex paleis et tritico. Ergo ecclesia habet paleas, id est homines peccatores. Et sic mixta est ex bonis et malis. In expositione huius loci omnes sancti tenent istam veritatem. Videndus etiam Augustinus super Ps. 25. in praefatione. Explicat ibi istam parabolam et dicit, Nemo ante tempus ventilationis deserat aream. Nedum non vult pati peccatores. Inveniatur foris et colligatur ab avibus antequam ${ }^{22}$ congregetur in horreum.

Primo patet ista conclusio Math. 13., Simile est regnum coelorum sagenae missae in mare et ex omni genere, etc. [fol. 40r] Et ibi Gregorius et alii sancti per sagenam intelligunt ecclesiam militantem. Iterum Matth. 25., Simile est regnum coelorum decem virginibus. Et ibi sancti. At vero tamen hic, quod illae imprudentes virgines dicuntur virgines. Certum, in scriptura boni solum dicantur communiter virgines, quia non sunt fornicati cum diabolo. At in illa parabola dicuntur virgines omnes fideles qui retinent veram fidem Christi, quia fides est corpus fidelis iuxta illud Iacobi, Sicut corpus sine anima, ita fides sine operibus. Charitas vero est sicut anima. Et quia fideles omnes retinentes veram fidem retinent integritatem sui corporis, scilicet fidei, sicut virgines retinent integritatem corporis, ideo omnes fideles sunt virgines licet non habeant charitatem.

Item quia in scriptura hi proprie et principalius fideles dicuntur fornicari quando deserunt veram fidem sicut dicebat propheta, Hi autem forticatores cum amatoribus multis; id est, cum diis multis relecta fide. Fideles ergo, quia retinent veram fidem, non dicuntur fornicari, sed virgines. Et ideo ecclesia licet habeat in se malos, appellatur virgo. Et sic Paulus, Despondi vos uni viro virginem istam exhibere Christo. Quamuis enim aliqui non retineant castitatem charitatis, retinent tamen castitatem fidei.

Probatur. Patet ex Paulo 1. ad Cor. et etiam 2. ad Cor. Scribit ecclesiae et totam congregationem illam appellat ecclesiam Dei et sanctam. Cum tamen essent ibi plures peccatores, ut patet ex contextu, quia reprehendit illos, et etiam patet de illo fornicario.

Probatur. Ista est constans sententia omnium sanctorum. Augustinus scripsit de hac re plura, quia Donatus haereticus habuit istam haeresim quam modo habent lutherani. Ita refert Augustinus lib. de haeresibus. Et sic scripsit plura [fol. 40v] contra donatistas. Videndus est etiam Augustinus, quod ibi loquitur Christus in persona suae ecclesiae, Fideles qui videbant me per scripturas, fugerunt a me. Dicit Augustinus quod clarius et apertius locuti ${ }^{23}$ sunt prophetae de unitate ecclesiae quam de ipso Christo.

\footnotetext{
22 Sigue palabra tachada.

${ }^{23}$ Ms. loquti.
} 
Et hoc, ait, factum est quia praevidit Spiritus sanctus quod haeretici plures lites erant excitaturi contra ecclesiam quam contra Christum ut heretici non praetendant excusationem, sed in iudicium veniant, quia foras fugerunt.

Dico ergo quod hac tempestate et inter nos etiam ideo scandalizantur haeretici quia vident quamplures peccatores in ecclesia et vident praelatos non habentes curam omnium, et ideo putant quod haec non est ecclesia; unde existimantes se esse granum, egrediuntur $a b^{24}$ area et colliguntur $a b$ avibus haeresum.

Probatur. Patet ista sententia quia Christus ex hominibus instituit suam ecclesiam. At vero in omni republica humana sub eodem rege et regno sunt alii servantes leges regni et aliqui non servantes, et propter hoc non desinunt pertinere ad regnum. Ergo idem est etiam in ecclesia Christi. Patet consequentia quia Deus disponit omnia suaviter.

Probatur. Patet. [Ecclesia est visibilis.] ${ }^{25}$ Quia ecclesia et sit visibilis et quod sit mixta bonis et malis. Quia sacramenta sunt columnae et fundamenta ecclesiae. At vero sacramenta sunt signa externa et sensibilia. Item homines christiani communicant exterius et recipiunt sacramenta ecclesiae. Ergo ipsa ecclesia est etiam sensibilis et exterior. Consequentia est evidens. Rursus in sacramentis communicant tam boni quam mali. Ergo omnes illi pertinent ad ecclesiam. Probatur quia ministri sacramentorum sunt et boni et mali. Ergo [fol. 41r] etiam illi qui recipiunt sacramenta. Antecedens est de fide contra haereticos. Est hic prae oculis habenda illa sententia Christi Matth. 23., Super cathedram Moysi ascenserunt scribae et pharisei; que dicunt facite etc. Ergo et prelati etiam sunt mali.

[3.] Sed contra istam veritatem sunt argumenta haereticorum. Probatur. Arguitur ex articulo fidei quo credimus sanctam ecclesiam catholicam et apostolicam. Item etiam Paulus appellat ecclesiam sanctam et immaculatam Eph. 5., ut exhiberet sibi gloriosam ecclesiam non habentem maculam, etc. Ergo peccatores non sunt ecclesia. Probatur quia nos credimus istam sanctam eclesiam Fides vero est de non visis. Ergo eclesia catholica invisibilis est.

Ex hoc fundamento colligunt lutherani quod omnis cultus exterior et caerimonie exteriores et templa sunt paleae et sunt nihil. Quia, aiunt, ecclesia est invisibilis. Ergo debet habere cultum invisibilem. Ex hoc etiam infe-

\footnotetext{
24 Ms. ab ab. Repeticiión.

25 Lo colocado entre corchetes dentro del cuerpo del texto se halla en el msnuscrito al maren.
} 
runt quod nullae sunt leges positivae istae externae, nullus praelatus, nullus papa. Unde solum recognoscunt Deum et Christum tanquam praelatum et papam. Et probant ex illo Ioan. 4. Dixit Christus, Venit hora quando veri adoratores adorabunt Patrem in spiritu. Et illud, Eos qui adorant eum, in spiritu et veritate oportet.

Ad hoc argumentum respondetur quod ecclesia vocatur sancta principaliter ex duobus. Primo. Quia non dubium est nisi quod multoties illa verba referuntur ad eos qui sunt in gratia. Et sic tamen ecclesia denominatur sancta non a maiori parte, sed a potiori, sicut in communi modo loquendi quando quis contionatur ubi sunt aliqui duo vel tres illustres, etsi maior pars sit ignobilis, solet dicer: nobilissima contio. Ita etiam est in sacris literis, ut in Paulo, iste modus loquendi.

Probatur. Sicut ecclesia sancta et omnes Christiani etiam peccatores [fol. 41v] omnes dicuntur sancti, non quia habeant perfectam sanctitatem, sed quia omnes sunt baptizati et professi sunt religionem sanctissimam, sicut omnes etiam monachi etiamsi sint prophani, dicuntur religiosi propter suum officium, et papa dicitur sanctissimus propter officium. Ita omnes Christiani dicuntur sancti.

Probatur. Dicuntur sancti maxime quia habent fidem et spem, quia fides est donum Dei. Haeretici vero etiamsi fuerint baptizati non dicuntur sancti. Fideles vero dicuntur sancti. Sicut dixit s. Thomas art. 9. ad 3. quod omnes christiani vere dicunt: Credo in Deum, et illi etiam qui sunt numero et merito de ecclesia. Et illi etiam soli qui sunt solo numero de ecclesia quia dicunt in persona totius eclesiae. Est ergo advertendum in scripturis divinis quod aliquando verba referuntur ad omnes, aliquando vero referuntur ad solos iustos.

Ad aliud ex Paulo respondetur quod ille locus intelligitur primo de ecclesia ut accipiatur pro iustis. 2. ${ }^{\circ}$. Augustinus explicat eleganter istum locum et dicit quod Paulus ibi loquitur de ecclesia non secundum presentem statum quem habet aut habitura sit in hoc mundo, sed secundum statum quem tendit quia quamdiu sumus in corpore, semper ecclesia habet aliquam maculam, saltem peccatorum venialium. At vero Christus hoc intendit ut exhibeat Patri gloriosam eclesiam in alio seculo. Ita explicat Augustinus contra duas epistolas Pelagii c. 7. et lib. de perfectione iustitiae contra pelagianos asserentes posse esse iustus absque venialibus.

Ad illud respondetur quod sicut ipse Christus qui est caput nostrum erat visibilis ex humilitate, invisibilis autem divinitate, et sic apostoli aliud videbant, aliud credebant. Videbant ergo hominem et credebant illum esse Deum, sicut dixit Christus, Quia vidisti me, Thoma, credidisti. Ita etiam [fol. 42r] dicendum est de corpore Christi, scilicet ecclesia. Videmus istam con- 
gregationem visibilem adunatam sub sacramentis visibilibus, sub praelatis visibilibus, sub confessione externa fidei, sub cultu et caerimoniis visibilibus, aliud vero credimus, scilicet quod habet in se fidem, spem et charitatem. Et credimus quod regitur Spiritu sancto. Et quia in ista infirmitate est fortitudo eius, et credimus quod ista ecclesia habet dona invisibibilia coelitus data. Et idem dicemus de praelatis quia in illis abscondita est eclesiastica potestas et virtus divina.

[4.] Ex hoc sequitur quod ista ecclesia Christi habet in terris unum caput visibile, videlicet unum praelatum qui est summus pontifex, episcopus scilicet romanus. Hoc patet quia ubi est multitudo sine ordine est confusio, quae tamen non est admittenda in republica christiana. Sed ecclesia Christi est multitudo fidelium. Ergo in illa est ordo. Et sic in illa debent esse subditi et praelati. Et debet esse unus summus praelatus qui praesit omnibus sicut videmus contingere in regno temporali. Sicut etiam in universo invenimus partes proxime alie universales et Deus suprema omnium causa, hoc etiam patet ex verbis Christi Matth. 16., Tibi dabo claves, etc. Et Ioan. ultimo dixit Petro: Pasce oves meas.

Hoc etiam asserunt omnia concilia. Videndum concilium constantiense, praesertim circa errores Ioannis Us, et in bulla Martini 5.i interrogationes. Una est utrum credat quod Petrus fuerit vicarius Christi, et subdit utrum credat quod papa sit successor Petri habens supremam potestatem in ecclesia Dei. Ex quibus verbis advertendum est quod diximus in materia de legibus, quod Pontifex Romanus non est successor Christi, sed est vicarius Christi; successor vero Petri, quia successor alicuius dicitur quando alius mortuus est vel motus est a dignitate. Unde quia pontifices romani decedunt per mortem, alii dicuntur eorum succesores.

[fol. 42v] At vero quia Christus vivit et est pontifex in aeternum, dico, Papa non est successor eius, sed vicarius, sicut modo in regno princeps nostrorum non est successor Philippi, sed vicarius ${ }^{26}$. Philippus vero est succesor patris qui obiit. Hoc ait Paulus Hebr. 7., Plures facti sunt sacerdotes eo quod morte prohiberentur permanere. Hic autem scilicet Christus, eo quod maneat in eternum, sempiternum habet sacerdotium, etc. Est ergo Christus noster pontifex et caput. Romani vero pontifices sunt eius vicarii.

Ex his solvitur argumentum haereticorum dicentium quod ex hoc quod ponimus papam esse caput ecclesiae facimus corpus monstruosum cum duobus capitibus, Christus scilicet et papa. Respondetur quod nos unum caput praecipuum habemus, scilicet Christum. At vero papam poni-

${ }^{26}$ Ms. vicaria. 
mus tanquam caput vicarium et subalternum, sicut est modo in nostro regno et nulla ex hoc sequitur monstruositas, sed potius pulchritudo. Alias enim non potest gubernari bene ecclesia. Non enim bene gubernaretur etiam per servos Christi dispersos per orbem nisi illi servi essent interordinati sub suo capite.

Ex his sequitur $3 .^{\circ}$ quod ecclesia Christi est una, non plures. Hoc patet ex illo, Una est columba mea, sponsa mea. Probatur Rom. 12. et 1. Cor. 12. et Ephe. $4 .^{\circ}$ et $5 .^{\circ}$. Et alibi frequenter Paulus dicit quod ecclesia est corpus Christi mysticum et non plura corpora. Una est eclesia Christi, non plures.

Hoc etiam formaliter in articulo fidei: Credo sanctam eclesiam, non ecclesias. Et in concilio nicaeno explicatur amplius cum dicitur: Credo unam sanctam et apostolicam eclesiam. Et Christus dixit, Erit unum ovile et unus pastor. Ergo sicut habemus unum papam, ita habemus unam ecclesiam. At vero quod Paulus dicit, Sicut in omnibus eclesiis doceo, et illud, Ipsum dedit caput super omnem ecclesiam, et illius ecclesiae quae est Corinthii.

Respondetur quod est sermo de partibus ecclesiae quae partes sic habent nomen totius ecclesiae. [fol. 43r] Quia quaelibet pars ecclesiae est congregatio fidelium, ideo vocatur ecclesia. Sed absolute loquendo una est ecclesia.

Hinc sequitur quod nostra ecclesia modo est magis una quam fuit ante adventum Christi quia ante adventum Christi erat unica spiritualiter quodam modo, scilicet per fidem, spem, et charitatem. At vero exterius non erat una congregatio sub eodem praelato et eisdem sacramentis, sed sub diversis. Quia iudaei habebant circumcisionem et erant sub suo pontifice. Gentiles vero, qui poterant etiam salvari extra populum iudaeorum, non habebant illorum sacramenta neque praelatum. At vero in ecclesia nostra ex populo iudaeorum et ex populo gentilium facta est una eclesia sub uno pastore, sicut dixit Christus. Alias oves habeo quae non sunt, etc. Et erit unum ovile et unus pastor. Et sic Christus fecit utraque unum.

Ex his sequitur integra descriptio eclesiae. Eclesia catholica militans est congregatio fielium sub una fide sub eisdem sacramentis, sub uno capite Christo in coelo et sub uno eius vicario, scilicet romano pontifice, in terra. Quicumque autem extra istam congregationem est, non est in ecclesia Christi, sed in synagoga Satanae; non est in Hierusalem, sed in Egypto et Babilonia, in tenebris et confusione.

Ex hac definitione sequitur contra hereticos quod, sicut habemus ecclesiam visibilem et pontificem universalem, ita etiam habemus templa visibilia que appellantur iglesias accipiendo continens pro contento. Habemus etiam sacrificia visibilia. Item, cultum visibilem et sacerdotes visibiles. 
Item, laudes Dei et cantica sensibilia. Item, habemus leges positivas, sensibiles et audibiles, et reliqua omnia que profitemur contra heereticos lutheranos qui ponunt omnia invisibilia. Sequitur etiam quod debemus et posumus habere concilia visibilia ad tractandas res fidei.

De his fundamentis, preesertim de unitate capitis egimus in materia de clavibus q. 17. Videndus Turrecremata lib. de summa ecclesiae. 
tha 